\title{
Hour Times Picogram per Milliliter per Microgram
}

National Cancer Institute

\section{Source}

National Cancer Institute. Hour Times Picogram per Milliliter per Microgram. NCI

Thesaurus. Code C85637.

Hours times picograms per milliliter per microgram. 